\title{
DISTORÇÕES FLEXÍVEIS DO DIREITO AMERICANO, OU COMO SÃO PAULO E SÃ̃O JOÃO INFLUENCIAM A POLÍTICA SOCIAL FUNDAMENTAL
}

\author{
FLEXIBLE DISTORTIONS OF AMERICAN LAW, OR HOW ST. PAUL AND ST. \\ JOHN INFLUENCE FUNDAMENTAL SOCIAL POLICY*
}

\author{
Richard H. Weisberg ${ }^{* *}$
}

\begin{abstract}
RESUMO: este artigo busca demonstrar como preservar a possibilidade de uma mudança saudável dentro dos limites interpretativos, por meio da restauração gradual de cinco leituras flexíveis equivocadas da Constituição dos EUA.
\end{abstract}

PALAVRAS-CHAVE: Constituição americana. Direito americano. Leituras equivocadas flexíveis. Limites interpretativos.

ABSTRACT: This article aims to demonstrate how to preserve the possibility of a laudable change within interpretive limits, through the gradual restoration of five flexible misreadings of the US Constitution.

KEYWORDS: American law. Flexible misreadings. Interpretive limits. US Constitution.

Como Sanford Levinson demonstrou de forma excelente, para muitos norteamericanos de hoje em dia a "história sagrada" não é nem bíblica nem literária: é a Constituição dos Estados Unidos da América (LEVINSON, 1988). Debates sobre como interpretá-la atingiram paralelos extraordinários com a interpretação bíblica e em muitos casos foram igualmente controversos. ${ }^{1}$ Também, vigorosos debates têm gerado teorias duvidosas em ambos os campos. No direito constitucional, estamos inclinados a contrastar os teóricos originalistas e os teóricos da constituição viva (living constitutionalists). Os Red staters ${ }^{2}$ e/ou constitucionalistas de uma estirpe conservadora enaltecem os construcionistas estritos, ou seja, aqueles que tendem a se ater (ou, ao menos, fingem) ao texto e à intenção original, que

\footnotetext{
* Este artigo é a versão escrita da conferência proferida pelo professor Weisberg na Aula Magna do Curso de Direito da UFPR, no dia 11 de março de 2014. Quando o professor faz, no artigo, menção a capítulo e livro, refere-se ao então no prelo In Praise of Intransigence: The Perils of Flexibility, que viria a ser publicado pela Oxford University Press em 13/05/2014 (N. do E.). Tradução da conferência por William Soares Pugliese, mestre e doutorando pelo Programa de Pós-graduação da Faculdade de Direito da UFPR. Revisão da tradução por Katya Kozicki e Vera Karam de Chueiri, professoras da Graduação e Pós-graduação da Faculdade de Direito da UFPR.

** Walter Floerhsheimer Professor of Constitutional Law at Benjamin L. Cardozo Law School, NY.

${ }^{1}$ Cf., por exemplo, GREENAWALT, 2010 e PELIKAN, 2004.

2 Adeptos do Partido Republicano nos EUA. (N. do E.)

Revista da Faculdade de Direito - UFPR, Curitiba, vol. 59, n. 2, p. 9-30, 2014.
} 
de alguma forma serão encontrados nos textos constitucionais sagrados exatamente como foram escritos e ratificados, décadas e até mesmo séculos atrás. Por outro lado, intérpretes livres, quando juízes, são acusados de serem ativistas. Enquanto isso, os teóricos liberais e mais Blue-staters $^{3}$ dirigem aos originalistas a crítica de inflexibilidade, considerando-os insuficientemente abertos à Constituição Viva, que nunca foi mais bem definida do que pelo falecido Justice William Brennan em um artigo de 1986:

\begin{abstract}
Nós, juízes contemporâneos, lemos a Constituição da única maneira que podemos: como americanos do século XX. Nós olhamos para a história da época dos constituintes e para a história intervencionista da interpretação. Mas a questão final deve ser: o que as palavras do texto significam para o nosso tempo? A habilidade da Constituição não repousa em qualquer significado estático que poderia ter tido em um mundo que está morto e enterrado, mas na capacidade de adaptação dos grandes princípios para lidar com os problemas e as necessidades atuais (BRENNAN, 1988, p.17 et seq.). ${ }^{4}$
\end{abstract}

Eu sempre admirei a disposição de Brennan para admitir uma prática que evoca, pelo menos para mim, a técnica interpretativa de São Paulo e de São João. Talvez não seja coincidência que Brennan, um juiz altamente liberal e, com razão, admirado, participante da igualmente admirada e ativista Corte Warren da década de 1960, tenha recebido uma educação Católica. Deve-se ter uma habilidade quase jesuítica - e uma pequena dose de audácia $\left(\right.$ chutzpah $\left.^{5}\right)$ - para desancorar um texto sagrado do que parecia ter tido significados consagrados (a ênfase é intencional, como veremos) e se mover, ao contrário, em direção a uma voz interior que pode lidar com o novo e com o diferente. Mas a minha admiração pela Corte Warren e por este ilustre (e católico) membro deriva do que vou demonstrar aqui: aquela Corte, que nos deu Brown vs Board of Education (SUPREME COURT OF THE UNITED STATES, 1954), atuou principalmente com o propósito de restauração, e não de criação de significados.

Ainda, pode-se perguntar: como o nosso mundo constitucional pareceria se não tivéssemos nossos ativistas e se nossa Suprema Corte não brincasse ocasionalmente com a autoridade das interpretações anteriores? Não precisaríamos, justamente, dos São Pedros e São Joões, prontos para superar a insistência farisaica nos significados originais ${ }^{6}$ O ceticismo secular sobre o que chamo de flexifobia (flexiphobia) pode atingir o seu ápice quando consideramos um mundo constitucional habitado em grande parte, e muito menos exclusivamente, pelos construcionistas estritos. Separados mas iguais ainda poderia ser bom

\footnotetext{
${ }^{3}$ Adeptos do Partido Democrata nos EUA. (N. do E.)

${ }^{4}$ Cf. também o tratamento do tema por Jack M. Balkin em Living Originalism (2011).

${ }^{5}$ Palavra iídiche que expressa audácia, para o bem e para o mal. (N. do E.)

${ }^{6}$ Cf., por exemplo, Paul Brest (1980).
} 
direito, e o mundo de Jim Crow, de Faulkner ${ }^{7}$ (discutido no meu capítulo anterior), poderia persistir, com seus linchamentos, suas fontes de água colorida e suas escolas segregadas. Métodos medievais de tortura (outro tema que, infelizmente, requer discussão nestas páginas) poderiam ser usados para executar pessoas. $\mathrm{O}$ direito de escolha da mulher poderia não ser protegido. ${ }^{8}$ O relógio poderia regredir para o tempo em que o estilo de justiça do tea party ${ }^{9}$ podia vedar até mesmo o uso de contraceptivos por um casal, e assim por diante.

Identificando-me há muito tempo com o originalismo moderado ${ }^{10}$, quero mostrar, à luz desta tradição, como uma reverência ao texto e às intenções dos constituintes não é contraditória com a noção de mover a Constituição para frente, rumo a gerações que terão de viver com ela e passar por novos desafios e novas tecnologias. Eu adiciono e, em certa medida, inverto a forma habitual como quatro emendas constitucionais, aplicadas em cinco casos reais aqui analisados, foram interpretadas. Em muitos casos, especialmente aqueles que lidam com a equal protection clause, os analistas tendem a concluir que só uma Suprema Corte maleável, não originalista, poderia corrigir erros anteriores feitos por Justices conservadores e, ao fazê-lo, mover essas emendas em direção aos séculos XX e XXI. A mais recente correção foi descrita, e condenada ou louvada por tal, como ativismo judicial, desvinculada do texto ou da intenção. Eu defendo, em vez disso, que os julgamentos soltos do texto e da tradição trouxeram uma doutrina antiprogressista e antitextualista e, assim, exigiram décadas de trabalho duro para restaurar o que deveria ter sido o significado original. A frouxidão, ou mesmo, por vezes, o constitucionalismo vivo desprendidos das origens não teriam sido necessários se os influentes juízes da época não tivessem deformado flexivelmente os significados originais nas decisões que, em seguida, tiveram que ser afastadas ou que ainda permanecem, aguardando o trabalho de restauração. Meu exemplo mais evidente desta última distorção envolve a Segunda Emenda (U. S. CONSTITUTION, 1791) e a habilidade da Suprema Corte atual que,

\footnotetext{
${ }^{7} \mathrm{O}$ autor faz referência ao romance Intruder in the dust, de 1948 (traduzido no Brasil como O Intruso e em Portugal como O Mundo Não Perdoa), do escritor americano William Faulkner (1897 - 1962). O romance centra-se em Lucas Beauchamp, um agricultor negro acusado de assassinar um homem branco, e que acaba inocentado por meio dos esforços de adolescentes negros e brancos e de uma solteirona de uma tradicional família do sul. Ele foi escrito como resposta de Faulkner - um escritor do sul - para os problemas raciais que esta região enfrenta. (N. do E.)

${ }^{8}$ Contudo, cf. a posição da Justice Ruth Bader Ginsburg, reiterada no início de 2013, de que a questão do aborto poderia ter sido deixada para o processo político e que Roe pode ter deixado para trás o total direito de escolha da mulher (JUSTICE Ginsburg's Misdirection, 2013). Parte do problema de Roe, para mim, foi o seu modo desajeitado, formal e estatisticamente, de localizar o direito que encontrou; mas esta tarefa foi bem, para não dizer brilhantemente, realizada pelo Justice Douglas em seu voto, que explica em poucas linhas o motivo pelo qual as mulheres devem ter o direito de autonomia sobre as decisões reprodutivas.

${ }^{9}$ Movimento que defende o originalismo, isto é, a interpretação do texto constitucional conforme o significado da época em que foi adotado. (N. do E.)

${ }^{10}$ Cf. WEISBERG, 1986, p. 993.
}

Revista da Faculdade de Direito - UFPR, Curitiba, vol. 59, n. 2, p. 9-30, 2014. 
semelhante à habilidade de São Paulo, encontra dentro do resistente texto um direito individual de possuir armas.

O primeiro tiro interpretativo feito pela Suprema Corte nas quatro emendas aqui tratadas errou o alvo por conta de distorções criativas de um tipo ou de outro. Nessa medida, os Justices se comportaram como os escritores do primeiro movimento de Jesus que discutimos. Eles permitiram que a sua visão excessiva e improvável subjugasse uma leitura justa dos textos em questão. E, como os primeiros escritores cristãos, eles alcançaram sucessos que, embora mantendo atração considerável para diversos públicos, provaram-se deletérios e às vezes tragicamente prejudiciais.

Eu preciso organizar meus argumentos insistindo que os meus leitores façam um voto, uma espécie de credo. Vocês devem aceitar que a Constituição é um documento estruturante, duradouramente útil e ocasionalmente inspirador, ainda que nós, o povo, desloquemo-nos cronologicamente para longe de sua fundação e para esta segunda década do século XXI. Talvez exemplificando a fé constitucional do Professor Levinson, ${ }^{11}$ e como alguém que ensinou direito constitucional por quase quatro décadas (15\% do tempo de existência do texto), eu permaneço como um verdadeiro crente.

Feito este voto, por meio de um ato de razão ou fé, ou alguma combinação de ambos, peço-lhes para adotar dois corolários. Primeiro, considerem que a interpretação constitucional também pode ser dividida em linhas religiosas. O Professor Levinson oferece seu equivalente sectário das dicotomias estrita/solta ou passiva/ativista: para um leitor de textos sagrados do tipo protestante, os desvios do sentido original do documento sagrado precisam ser justificados, principalmente porque intérpretes autorizados, tais como juízes da Suprema Corte (ou prelados papistas) nunca precisam enfrentar as pessoas afetadas pelas suas decisões. Por outro lado, porém, há um caminho católico de interpretação da Constituição. Como todo o meu livro sustentou, graças aos Santos Paulo, João e outros, como São Pedro, alguns leitores (como Justice Brennan, talvez) podem ter optado por essa tradição, que autoriza afastamentos do texto literal ou da intenção provável: a classe sacerdotal, geralmente não eleita, começa a decidir de acordo com as suas premissas, frequentemente não declaradas, o que um texto significa. ${ }^{12}$

${ }^{11}$ O professor Levinson há muito abandonou a sua fé (LEVINSON, 2006), o que ele elabora em Framed (Id., 2012).

12 (Id., 2006). O Professor Levinson (2012, p. 272 et seq.) reitera as analogias religiosas conectadas à interpretação constitucional em Framed. 
Meu segundo corolário é totalmente secular, eu mencionei uma versão dele no Capítulo 2, na discussão acerca do recente livro de Gutmann e Thompson sobre compromisso, e ele envolve uma distinção entre regras, que são bastante absolutas, e princípios, que orientam de forma mais flexível os juízes àquilo que consideram ser a resposta certa. Devemos a versão mais recente desta formulação ao grande filósofo do direito, Ronald Dworkin $^{13}$. Regras, embora sujeitas a algumas texturas abertas, como o positivista H. L. A. Hart $^{14}$ as chamou, geralmente pedem um único teste fundamental para o direito, enquanto os princípios muitas vezes envolvem uma chamada para a tomada de decisão com base em fatores que não são necessariamente a lei escrita ou um precedente. Dois exemplos familiares devem ser reiterados aqui.

Primeiro, as mulheres em A Jury of Her Peers ${ }^{15}$, vocês devem se lembrar, continuaram a sofrer com a invocação de um princípio antifeminista enfatizado, décadas anteriores, pela Suprema Corte. Em vez de adotar a regra dada pelo texto literal da Décima Quarta Emenda (U. S. CONSTITUTION, 1868), que prevê a igual proteção das leis, o Justice Bradley, da Suprema Corte, optou por uma idéia norteadora mais flexível: ele tirou do seu chapéu o dogma de que o "lugar da mulher é em casa" e impediu Myra Bradwell de se juntar à ordem dos advogados de Illinois. ${ }^{16}$

Segundo, a Igreja Católica na Europa de Hitler evitou, explicitamente, suas próprias regras contra o racismo e aconselhou o governo de Vichy de forma que ele poderia continuar a legislar contra os judeus de acordo com o princípio mais flexível da realpolitik (MARRUS; PAXTON, 1981).

Seja qual for o vocabulário, religioso ou secular, eu desafio a suposição simplista de que só interpretações flexivelmente criativas (leia-se: ceticismo às regras, ou católico), que parecem desafiar o sentido original do texto constitucional, nos levam para onde precisamos estar para fundamentar a fé naquele documento, bem como em certas tradições que fluem dele, como o tabu da tortura. Em outras palavras, e estou longe de ser o primeiro a dizer isso, a oposição entre construcionistas estritos e soltos da Constituição é enganadora, especialmente se

\footnotetext{
${ }^{13}$ Cf., por exemplo, DWORKIN, 1978, p. 14-80. Cf. BALKIN, 2011, n.3, p. 350: "O que motiva a distinção de Dworkin entre regras e princípios é se a norma em questão é mandatória ou se ela simplesmente tem peso."

${ }^{14}$ Herbert Lionel Adolphus Hart. (N. do E.)

15 O autor faz referência ao conto escrito em 1927 pela americana Susan Glaspell (1876 - 1948), vagamente baseado no assassinato de John Hossack, que Glaspell cobriu enquanto trabalhava como jornalista. O conto é visto como um exemplo de literatura feminista precoce, porque duas personagens femininas são capazes de resolver um mistério que as personagens masculinas não conseguem, auxiliadas por seu conhecimento da psicologia das mulheres. (N. do E.)

16 "A natureza das coisas", decidiu a Corte no caso Bradwell, era a de que as mulheres pertenciam à cozinha. Cf. Bradwell v. State of Illinois (SUPREME COURT OF THE UNITED STATES, 1872), voto do Justice Bradley.

Revista da Faculdade de Direito - UFPR, Curitiba, vol. 59, n. 2, p. 9-30, 2014.
} 
isso implica a equação estrito $=$ não-ativista $=$ conservador , enquanto solto $=$ ativista $=$ progressista e, especialmente, se somarmos a esta abordagem bipolar o que construcionistas estritos se revelam ao se manterem dentro dos limites do originalismo, enquanto os construcionistas soltos mostram suas cores de constitucionalistas vivos ao se libertarem de qualquer atenção para o que os homens de centenas de anos atrás poderiam ter escrito ou querido. A dicotomia apela para o discurso político e também foi estendida no sentido de que os conservadores querem o juiz como um árbitro imparcial, enquanto os ativistas normalmente não ligam para sua eventual criação do direito.

Como Stanley Fish afirmou há algum tempo sobre as políticas frequentemente opostas de contenção judicial e ativismo judicial:

Supõe-se frequentemente que uma indica respeito pela Constituição, enquanto a outra é um exercício indevido do poder interpretativo, influenciada pelo ponto de vista social e político; mas na verdade, a chamada restrição judicial é exercida pelos juízes que, por uma variedade de razões, decidem manter no lugar as interpretações com fundamentos sociais e políticos dos ativistas de uma geração anterior (Apud LEVINSON; MAILLOUX, 1988, p. 262).

Este capítulo é sobre aqueles antigos juízes ativistas da Suprema Corte, alguns agora considerados liberais e outros conservadores, que comandaram um texto constitucional até então não interpretado (ou pelo menos não com autoridade) e que erraram gravemente ao ir muito além do texto, chegando até a contradizê-lo, de modo que em alguns casos outras pessoas, ao longo de extensos períodos de tempo, tiveram que lutar muito para restaurar, em vez de mudar, os devidos significados. Eles são, nos termos deste livro, os Santos Paulo e João da interpretação textual, os infinitamente flexíveis que necessitam de correção ao longo do tempo por meio do trabalho de restauração de advogados e cidadãos comuns.

Começo este capítulo com um caso que ocorreu cerca de três décadas após a infeliz e quase advogada Myra Bradwell ver derrubada sua simples reivindicação de que a (então) recente Equal Protection Clause, da Décima Quarta Emenda, lhe garantisse um lugar no conclave masculino da Ordem dos Advogados de Illinois. Em Hans v. Louisiana (1890), o mesmo Justice Bradley que havia relegado Myra à cozinha reescreveu o texto da Décima Primeira Emenda de uma forma bizarra, dando início a problemas que ainda hoje estão sendo corrigidos. Em seguida, continuo com Plessy v. Ferguson (1896), Schenck v. U. S. (1919), Everson v. Board of Education of Ewing TP (1947), e District of Columbia et al. v. Heller (2008). Nos cinco casos, a Suprema Corte administrou mal o texto constitucional porque os Justices agiram de forma flexível, e não de forma estrita, e as suas decisões forçaram e 
continuam forçando os juristas a retornar e restaurar significados deliberadamente abandonados.

I. Em Hans v. Louisiana (SUPREME COURT OF THE UNITED STATES, 1890), o texto da Décima Primeira Emenda, ratificada em 1798, diz o seguinte:

O Poder Judiciário dos Estados Unidos não se entenderá como extensivo a qualquer demanda baseada na lei ou na equidade, iniciada ou processada contra um dos Estados Unidos por cidadãos de outro Estado, ou por cidadãos ou súditos de qualquer Estado estrangeiro (U. S. CONSTITUTION, 1798).

Sem dúvida, menos familiar aos meus leitores que o resto deste quinteto de decisões infelizes da Suprema Corte, Hans retomou a Décima Primeira Emenda 92 anos após ter sido ratificada. A Corte mudou seu significado enquanto supostamente afirmava preservá-lo ou, em nossos termos, ela "deu uma de São Paulo" sobre o texto antigo. Em vez de simplesmente restringir a competência dos tribunais federais contra queixas de estrangeiros contra os estados, Hans foi muito além e concedeu a imunidade aos estados em processos movidos por seus próprios cidadãos. $\mathrm{O}$ constitucionalista Jack Balkin descreve a conseqüência reconhecidamente complicada de traição do texto literal em termos abençoadamente simples:

Hans... parece ser incoerente com o texto constitucional... A doutrina atual lê "cidadãos de outros Estados" para incluir os cidadãos de um mesmo Estado [...] e também permite demandas de equidade por meio da ficção de ações contra o procurador-geral do Estado [...]. Talvez a melhor defesa de algum tipo de imunidade estatal seja um argumento estrutural para a proteção da soberania do Estado sob a Décima Emenda [...], mas não é de todo claro por que considerações estruturais devem produzir a doutrina que temos atualmente (BALKIN, 2011, n. 3, p. 454; n. 39).

O espantoso salto para longe do texto em Hans pretendia, ainda que incorretamente, restabelecer uma melhor política que ele sustentava ter prevalecido antes da adoção da Décima Primeira Emenda, e com base na qual mesmo um cidadão do próprio estado não poderia processá-lo em um tribunal federal. Mas o senso de história da Corte que julgou Hans foi distorcido e ela entendeu os fatos de forma incorreta. Na tentativa de demonstrar que os senhores feudais, o equivalente, digamos, dos nossos estados, não poderiam ser processados em seus próprios tribunais por seus súditos, que seriam o equivalente aos cidadãos de um estado, a decisão de Hans ignorou completamente o fato histórico de que os proprietários podiam ser processados nas Cortes do Rei, o equivalente à jurisdição do tribunal federal, garantida aos cidadãos de um estado contra este próprio estado pela interpretação literal da Décima Primeira Emenda (HOLDSWORTH, 1903, v. IX, p. 90). 
Tenho defendido que há um pedigree questionável datado do primeiro movimento de Jesus para as práticas interpretativas $\operatorname{amplas}^{17}$ e eu continuarei a mostrar que estas práticas desnecessariamente atrasaram a implementação de políticas efetivas que deveriam ter derivado quase que diretamente do texto e da história de outras Emendas mais conhecidas; ao inverso, como quando o Justice Bradley instruiu a Sra. Bradwell de que o lugar dela era em casa, os afastamentos amplos do texto resultaram em doutrinas desastrosas que exigiram muito suor e compromisso para serem derrubadas. A má interpretação criativa da Décima Primeira Emenda pelos Justices em Hans v. Louisiana exigiu correção restauradora das Supremas Cortes posteriores, incluindo especialmente aqueles que se sentaram sobre a Corte ativista que nos trouxe (como veremos) Brown v. Board of Education (SUPREME COURT OF THE UNITED STATES, 1954). Depois de algum trabalho duro, esses juízes encontraram renúncias implícitas dos estados à imunidade que Hans lhes tinha concedido sem qualquer suporte textual ou histórico ${ }^{18}$.

Vamos agora encontrar a mesma estrutura de restauração à medida que avançamos para a linguagem mais familiar da Décima Quarta Emenda. No período imediatamente após a Guerra Civil, uma cláusula de igual proteção foi adicionada, e pela primeira vez a igualdade tornou-se um princípio fundamental na Constituição dos EUA. O quão fundamental era esse princípio, no entanto, quando juízes como Bradley, que já haviam se situado contra o texto quando Myra Bradwell procurou admissão à Ordem dos Advogados de Illinois, apontaramlhe seus machados de dois gumes?

II. Em Plessy (SUPREME COURT OF THE UNITED STATES, 1896), a mesma Equal Protection Clause que o Justice Bradley havia mutilado foi novamente distorcida quando a Suprema Corte votou para permitir que as instalações públicas seguissem uma política de separados mas iguais. Olhando para o texto da Décima Quarta Emenda (U. S. CONSTITUTION, 1868) - "nenhum Estado pode [...] negar a qualquer pessoa sob sua jurisdição a igual proteção das leis" -, o Tribunal tinha uma escolha, e optou pela alternativa errada. Plessy começou por distorcer ou ignorar alguns fatos importantes do caso concreto;

\footnotetext{
${ }^{17}$ Da caneta de outro recente analista da Décima Primeira Emenda, Michel Landau (2012, p. 513): “A décima primeira emenda da Constituição dos Estados Unidos da América foi sujeita a algumas das mais contorcidas e infundadas interpretações constitucionais [...] Ao longo dos anos - frequentemente em razão de sua composição - a Suprema Corte variou respostas sobre o que a linguagem significa, quais pedidos são indeferidos, e qual relação tem a emenda com outras leis."

${ }^{18}$ Cf., por exemplo, Justice Douglas em Petty v. Tennessee-Missouri Bridge Commission (SUPREME COURT OF THE UNITED STATES, 1959), em que a Corte encontrou uma renúncia tácita da imunidade do estado aos processos ajuizados por estrangeiros dos estados; e Parden v. Terminal Railroad Co., (SUPREME COURT OF THE UNITED STATES, 1964), em que a Corte interpretou uma legislação, voltada ao emprego no Congresso, para conceder um direito a recurso, mesmo contra o estado que seria imune à luz de Hans.

Revista da Faculdade de Direito - UFPR, Curitiba, vol. 59, n. 2, p. 9-30, 2014.
} 
sob o fundamento da lei de Luisiana que fora questionada, Homer Plessy tinha sido removido de um vagão de trem só para brancos porque ele tinha um oitavo de cor, mas a Corte não tomou conhecimento do fato de que nenhuma pessoa branca voluntariamente sentada em um carro de cor teria sido igualmente forçada a se retirar. Por outro lado, babás de cor estavam isentas da separação se estivessem cuidando de bebês brancos. Omissões e distorções factuais não são exclusividades da metodologia interpretativa de Plessy e, como vimos quando o primeiro movimento de Jesus se beneficiou de erros de tradução e manipulação histórica, tais erros ajudam a produzir uma doutrina indesejada. Com efeito, Plessy contornou a conclusão de que as políticas raciais das ferroviárias e suas instalações não eram realmente separadas e muito provavelmente não eram iguais. A Corte entendeu que a cláusula de igual proteção estava efetivada por leis estaduais e municipais que separavam as raças em locais públicos.

O predicado fático de separados mas iguais já era falso, e a Corte lançou décadas de sofrimento sob o título de $\operatorname{Jim}$ Crow $^{19}$. Uma análise menos flexível do simples texto da Décima Quarta Emenda deveria ter evitado o resultado alcançado em Plessy, muito menos baseado nas regras. Ao contrário, com apenas Justice Harlan vencido, a Corte disse:

O objeto da [Décima Quarta] Emenda foi, sem dúvida, fazer cumprir a igualdade absoluta das duas raças perante a lei, mas na natureza das coisas, não poderia ter sido destinada a abolir as distinções baseadas na cor, ou para impor a igualdade social, em distinção à igualdade política, ou uma mistura das duas raças sobre termos insatisfatórios para ambas. As leis que permitem, e mesmo que exigem a sua separação em lugares onde eles são suscetíveis de serem postos em contato não implicam, necessariamente, na inferioridade de uma raça em relação à outra (SUPREME COURT OF THE UNITED STATES, 1896, grifos nossos).

O texto da Décima Quarta Emenda, lido fielmente, poderia ter sido melhor interpretado para derrubar uma lei como a de Luisiana, que forneceu uma igualdade espúria por meio da separação. O trabalho escorregadio de se ater ao caminho oposto dependia de frases como as que enfatizei. A Corte, ao se encarregar de descobrir a Emenda usando princípios vagamente articulados por ela própria, talvez verdadeiramente racistas, divorciou-se de premissas que poderiam ser estabelecidas pelo próprio texto da Constituição.

Separação não significa "necessariamente" desigualdade, dizia a Corte, sem qualquer ingenuidade. Mas se esse pudesse ser o significado para uma pessoa de cor recentemente libertada, a política segregacionista não deveria se submeter ao texto constitucional? A frase

\footnotetext{
${ }^{19}$ As leis de Jim Crow foram institutos de segregação racial promulgados entre 1876 e 1965 nos Estados Unidos, em nível estadual e local. Elas estabeleciam uma segregação racial de jure em todas as instalações públicas nos estados do sul da antiga Confederação, havendo, a partir de 1890, um status de "separados mas iguais" para os afro-americanos. (N. do E.)
}

Revista da Faculdade de Direito - UFPR, Curitiba, vol. 59, n. 2, p. 9-30, 2014. 
vaga da maioria, "natureza das coisas", indica que - não pela última vez na história ${ }^{20}$ significados socialmente importantes seriam derivados do espírito de um texto, algo a ser encontrado dentro da subjetividade dos Justices, e não a partir do texto em si ou das intenções prováveis de quem os escreveu e ratificou.

A frase "igual proteção das leis", como afirmou o dissidente solitário John Marshall Harlan, significa que ninguém, sob a lei, pode ser expulso de qualquer lugar, por qualquer pessoa, apenas por causa de sua raça. E isso é especialmente verdadeiro tendo em conta que a Décima Quarta Emenda foi destinada a beneficiar os escravos recém-libertados contra a opressão de estados como a Luisiana. Assim, para Harlan, dissidente em Plessy, houve esta realidade flexifóbica: "No que diz respeito aos direitos civis, todos os cidadãos são iguais perante a lei. [Essa decisão] derrotará os fins beneficentes que o povo dos Estados Unidos tinha em vista quando adotou as recentes alterações da Constituição" (SUPREME COURT OF THE UNITED STATES, 1896).

Como de costume, vozes proféticas chamam seus colegas para resgatar o significado textual ao invés de desviar-se dele! Quanto trabalho de intransigência foi necessário para restaurar, primeiro para os negros e em seguida para as mulheres e, em seguida, para gays e lésbicas, significados que já eram inerentes ao texto que está sendo interpretado!

O difícil caminho para uma restauração justa da verdade de Harlan foi contado e recontado, e [a restauração] é especialmente inspiradora quando se enfatiza o trabalho duro de advogados teimosos como Thurgood Marshall, que trabalhou incansavelmente para acabar com o separados mas iguais $^{21}$, e de juízes de cortes federais do sul, que intransigentemente provocaram mudanças mesmo diante de dura resistência ${ }^{22}$.

Para muitos, a decisão de 1954 em Brown v. Board mostrou que as leituras "rígidas" da Constituição ficaram no caminho do progresso e que os resultados corretos fluíram de leituras flexíveis desapegadas ao texto ou à história. Para outros, como o meu professor de direito favorito, Herbert Wechsler, Brown errou, não por causa de sua decisão, mas sim porque a sua fundamentação violou o que ele chamou de "princípios neutros" (WECHSLER,

\footnotetext{
${ }^{20}$ O juiz flexifóbico Lothar Kreyssig heroica e abertamente lamentou a tendência de os juízes da era nazista ignorarem as regras sob as quais foram formados e de determinarem resultados de acordo com o princípio daquilo que o Führer gostaria.

${ }^{21}$ Cf., dentre várias citações da história flexifóbica de Plessy, a Brown story, em HIGGENBOTHAM JR., 2000.

22 Temos que celebrar cada juiz distrital no sul que se manteve fiel a Brown durante os explosivos anos de 1954 a 1965, até que os núcleos políticos finalmente se tornaram ativos em apoiar a decisão - Eisenhower havia enviado tropas para dessegregar a Universidade do Alabama, mas aquele foi o ponto alto anterior. Cf., por exemplo, o obituário do juiz Frank M. Johnson (1999, p. A12).
} 
1959, p. 1). Ele se preocupava porque viu uma base analítica insuficiente para o afastar de Plessy, a decisão vinculante no caso em análise.

Ambos os lados em debate evitaram uma análise mais simples, a que celebraria totalmente o resultado de destruição do apartheid em Brown, enquanto, decididamente, não concluía que a Corte violava métodos abrigados e neutros de ler a Constituição e os precedentes! Brown não foi uma decisão flexível em relação ao texto, mas um retorno a ele. Seu "princípio neutro" foi a restauração da regra que já podia ser encontrada na Décima Quarta Emenda. Se Justices menos flexíveis em Plessy tivessem resolvido este caso textualmente já no início, então Brown não teria sido necessário. A virada feliz em 1954 não era de anarquia judicial, mas sim um retorno ao texto e à intenção, não em direção à flexibilidade judicial infinita, mas sim em direção à intratabilidade.

III. Schenck (1919) e IV. Everson (1947), dois casos relacionados à Primeira Emenda, demonstram problemas semelhantes causados por más interpretações excessivamente flexíveis que demandaram décadas de uma - ainda em curso - melhora restaurativa. Schenck v. United States (SUPREME COURT OF THE UNITED STATES, 1919) e Everson $v$. NJ (SUPREME COURT OF THE UNITED STATES, 1947) interpretaram as seções destacadas da bem conhecida fonte da liberdade americana:

O Congresso não legislará no sentido de estabelecer uma religião, ou proibindo o livre exercício dos cultos; ou cerceando a liberdade de expressão, ou de imprensa, ou o direito do povo de se reunir pacificamente, e de dirigir ao Governo petições para a reparação de seus agravos.

Schenck havia sido preso sob uma lei federal, da época da Primeira Guerra Mundial, que criminalizava suas declarações escritas, nas quais ele manifestava oposição à empreitada da guerra. O texto da Primeira Emenda (U. S. CONSTITUTION, 1791) não o protegeria da pena? O que poderia ser mais simples para o intérprete? Assim como Isaías ${ }^{23}$ quer dizer o que ele diz e não um profundo prenúncio de uma vida individual 800 anos depois do que ele escreveu, do mesmo modo, os constituintes diziam nenhuma lei. Mesmo que alguns atos de fala, obviamente, não tenham sido protegidos da responsabilidade criminal - como a fraude, por exemplo - o discurso político como o de Schenck repousa no centro da Emenda, cuja ideia é proteger o discurso dissidente e impopular da poderosa mão censuradora do governo federal.

Imprevisivelmente, dada a Primeira Emenda, mas previsivelmente quando recordamos os séculos de deformação textual durante emergências, a pena de prisão de

\footnotetext{
${ }^{23} \mathrm{O}$ autor faz referência ao profeta que teria vivido entre 765 a. C. e 681 a. C. (N. do E.)
} Revista da Faculdade de Direito - UFPR, Curitiba, vol. 59, n. 2, p. 9-30, 2014. 
Schenck foi confirmada. Para racionalizar um desvio tão flexível do texto e das intenções dos constituintes, o Justice Oliver Wendell Holmes afirmou que a Primeira Emenda não protegeria alguém "gritando fogo falsamente em um teatro lotado". Se o governo pode punir tal ato de fala, concluiu este Justice oracular - três vezes ferido na Guerra Civil e o oráculo de Delfos de todos os juízes - certamente pode punir Schenck, cujos panfletos causaram um "perigo claro e iminente" de danos que o Congresso tinha o direito de proibir.

Assim como as interpretações dos primeiros movimentos de Jesus na Bíblia eventualmente ganharam os corações de bilhões de pessoas, a invocação retórica de Holmes de uma emergência teve grande apelo retórico. Sua deriva autoritária, da regra da Primeira Emenda em direção a um princípio não textual de pânico em uma crise, teve enorme apelo.

Pense duas vezes, no entanto: primeiro, a maioria das pessoas responde a um mero discurso de perigo - por exemplo, atropelando uns aos outros em seu caminho para as saídas - sem primeiro confirmar a observação do mentiroso hipotético que grita? Quando você ouve um alarme de incêndio disparar no trabalho, qual é a sua reação? Quando um evangelista grita com você "O mundo vai acabar!" o que você faz? Se ele lhe diz para saltar da ponte de Brooklyn, você faz isso? Como já escrevi em outro lugar, os constituintes eram profundamente céticos a respeito do poder das meras palavras de levar as pessoas a agir quando de outra forma elas não o fariam; pois pensavam na linguagem como "um meio nublado" (WEISBERG, 1988, p. 188), ${ }^{24}$ insignificante em comparação com outros impulsos e atividades humanas. Eles sentiam que os governos fariam pior ao censurar, do que ao permitir, protestos e outras formas de mero discurso. Se você não permitir um panfleto, ou até mesmo um vazamento ocasional de informações através do discurso verdadeiro, muito pior ocorrerá quando surgirem meios mais violentos de oposição aos governos, porque o meio nublado do discurso foi suprimido. Holmes viola esta informação básica e originalista da Primeira Emenda.

Então, também, o que o exemplo do teatro lotado tem a ver com a oposição política de Schenck à Primeira Guerra Mundial? Ele não estava falando em lugares lotados, mas diante de recrutas que estavam no processo de conscrição e não tinham nenhuma razão para prestar-lhe atenção (Nenhum recruta mudou de idéia por causa de palavras de Schenck). Então, para ir daqui até lá, Holmes habilmente juntou a hipótese do teatro com a frase apelativa do "perigo claro e iminente" que formou a fundamentação do julgamento. Se o

\footnotetext{
${ }^{24}$ Citando The Federalist Papers \# 37 no meu On the Use and Abuse of Nietzsche for Modern Constitutional Theory (1988).
} 
protesto político tinha alguma chance de causar a recusa de alguns desses recrutas, a Corte considerou - e assim diminuiu a Primeira Emenda - que esse discurso não seria protegido.

Uma abordagem flexifóbica da Primeira Emenda teria se recusado a afastar a lei do poderoso texto de vedação à censura pelo governo. Levaram anos de trabalhos análogos ao de Plessy, passando por Brown, para trazer o entendimento de volta à ideia original da Primeira Emenda. ${ }^{25}$ Arrependido, no entanto, o próprio Holmes, sob a influência dos Justices Louis Brandeis e Learned Hand, recuou rapidamente. Ele inverteu a sua própria posição e começou a proteger o protesto político, embora geralmente em discordância do seu erro (em termos de flexibilidade) original. ${ }^{26}$ Muito pouco, muito tarde. As posteriores dissidências de Holmes / Brandeis nada fizeram para corrigir as punições de manifestantes políticos, candidatos presidenciais, anarquistas, marxistas e panfletários de todas as estirpes, cujas palavras podiam ser distorcidas pelo governo ao tamanho único do parâmetro do "perigo claro e iminente". A sabedoria original ressurgiu apenas em 1969, com Brandenburg v. Ohio, quando o excessivamente flexível e, portanto, perigoso "teste de perigo claro e iminente" foi rigorosamente restringido aos atos de fala que fossem, ao mesmo tempo, "dirigidos a incitar ou produzir ação ilegal e... suscetíveis de incitar ou produzir tal ação naquele momento" (SUPREME COURT OF THE UNITED STATES, 1969). Até mesmo gritar "fogo" em um teatro lotado - e muito menos a distribuição de panfletos políticos para amplas audiências ou defender, nas salas de aula, a derrubada violenta do governo - não mais se inserem na estreita exceção à Primeira Emenda.

Outra parte da Primeira Emenda também recebeu, de modo similar, uma interpretação incorreta em um caso de 1947 em que a relação entre Igreja e Estado foi totalmente testada na Suprema Corte. Em Everson ${ }^{27}$ (caso IV), alguns contribuintes de Nova Jérsei se opuseram ao dever de subsidiar o transporte público para estudantes católicos de e para as escolas paroquiais. Eles invocaram a "establishment clause", que é muito menos transparente em seu significado do que a "speech clause" que o Justice Holmes conseguiu evitar de forma escorregadia em Schenck.

Em um resultado um tanto bizarro, a Corte autorizou o estado a cobrar um imposto a favor da educação religiosa. A establishment clause, se isto significa alguma coisa, foi

\footnotetext{
${ }^{25}$ Cf., por exemplo, Gerald Gunther (1991, p. 1019, 1040 et seq.). Gunther foi instrumental ao elaborar motivos para a "insatisfação" de Holmes com seu próprio teste; cf. também o trabalho do mesmo autor (GUNTHER, 1975, p. 719 et seq.) sobre o juiz Learned Hand, que confidenciou a Holmes suas dúvidas acerca do recém decidido caso Schenck.

${ }^{26}$ Cf. Abrams v. U. S. (SUPREME COURT OF THE UNITED STATES, 1919).

${ }^{27}$ SUPREME COURT OF THE UNITED STATES, 1947.

Revista da Faculdade de Direito - UFPR, Curitiba, vol. 59, n. 2, p. 9-30, 2014.
} 
concebida precisamente para evitar os males que confrontaram os colonizadores, que recordavam a experiência inglesa de ter uma igreja estabelecida e que - mesmo sendo os americanos bastante religiosos ${ }^{28}$ - não gostavam da prática e queriam que Igreja e Estado fossem separados. Na época, tanto os secularistas (como Thomas Jefferson) quanto os líderes religiosos (como Roger Williams) defenderam o que cada um, a partir de pontos de vista diferentes, chamavam de "muro de separação", ${ }^{29}$ e que a partir de qualquer perspectiva buscava a imposição de suporte para a religião advindo dos cofres públicos. Estranhamente, a retórica de Everson refletia em todos os lugares um endosso desta metáfora, especialmente quando se tratava de avaliar uma imposição financeira dos contribuintes para subsidiar práticas religiosas - o próprio mal que a Primeira Emenda pretendia curar:

A cláusula de "estabelecimento de uma religião" da Primeira Emenda significa pelo menos o seguinte: nem um estado nem o Governo Federal pode criar uma igreja. Nem pode aprovar leis que ajudem uma religião, todas as religiões, ou que prefira uma religião em detrimento de outra. Nem pode forçar nem influenciar uma pessoa a ir ou a ficar longe da igreja contra a sua vontade ou forçá-la a professar uma crença ou descrença em qualquer religião. Nenhum imposto em qualquer quantidade, grande ou pequena, pode ser cobrado para apoiar quaisquer atividades ou instituições religiosas, seja como possam ser chamadas, ou qualquer forma que possam utilizar para ensinar ou praticar uma religião. Nas palavras de Jefferson, a cláusula contra a criação da religião foi criada com a intenção de estabelecer "um muro de separação entre a Igreja e o Estado" (SUPREME COURT OF THE UNITED STATES, 1947).

Estamos aprendendo que os termos "rigorosa" e "solta" quanto à interpretação da Constituição - e seus paralelos quanto a Justices "prudentes" e "ativistas" - podem ser enganosos, e que o conceito de flexifobia ajuda a desatar várias contradições complicadas quando usamos tais palavras. Em Everson, a interpretação "estrita" da Constituição teria cortado pela raiz a possibilidade de violações graves ao "muro de separação" entre Igreja e Estado. A autoridade do texto e os constituintes restavam mutuamente opostos a uma subvenção fiscal de tarifa de transporte destes alunos de e para suas escolas paroquiais.

Apesar de sua forte retórica, porém, a maioria em Everson confirmou a legislação em favor da Igreja Católica. As passagens de ônibus para a escola sectária são uma ninharia, mas exigir que um contribuinte secular as subsidie é uma enormidade.

${ }^{28}$ O Cardeal Timothy Dolan reiterou, no programa dominical norte-americano Face the Nation, da CBS, de 31 de março de 2013, a crença generalizada de que os americanos continuam a ser um povo religioso, embora conceda que há cerca de $20 \%$ que não possuem afiliação religiosa, atribuindo isto a "alguns problemas com a igreja". O vídeo e a transcrição (em inglês) podem ser vistos em $<$ http://www.cbsnews.com/news/face-thenation-transcripts-march-31-2013-religion-and-politics-on-easter-sunday/>.

${ }^{29}$ Cf. JEFFERSON's Wall of Separation Letter (Acesso em: 11 mar. 2014) para as origens do "muro de separação".

Revista da Faculdade de Direito - UFPR, Curitiba, vol. 59, n. 2, p. 9-30, 2014. 
Nós ainda estamos lutando esta luta. Nenhum Justice recente foi mais alerta para a estranha qualidade de Everson - que ainda tem autoridade persuasiva - do que Sandra Day O'Connor. Em um caso de 1995, em que se analisava se a Universidade de Jefferson, na Virgínia, poderia negar que a mensalidade de um estudante fosse destinada a uma publicação evangélica, O'Connor votou no sentido de forçar a instituição a pagar as despesas da publicação religiosa, apesar da "establishment clause". Ela estava em conflito, mas Everson deu-lhe consolo:

Everson fornece, talvez, a mais forte explicação ao princípio do não-financiamento:
"Nenhum imposto em qualquer quantidade, grande ou pequena, pode ser cobrado
para apoiar qualquer atividade religiosa...". No entanto, a Corte aprovou o uso de
fundos públicos, em um programa geral, para reembolsar os pais das tarifas de
ônibus das suas crianças que frequentavam escolas católicas. Apesar de haver quem
cinicamente repudie a decisão da Corte como sendo inconsistente com suas
manifestações [ela cita o Justice Jackson em dissidência para Everson: "o precedente
mais adequado é o de Julia, que, de acordo com relatórios de Byron, ao sussurrar 'eu
nunca vou consentir', consentiu”], a decisão reflete a necessidade de se pautar em
julgamentos - não simples categorias - quando dois princípios de pedigree histórico
e jurisprudenciais iguais entram em conflito inevitável (SUPREME COURT OF
THE UNITED STATES, 1995, voto da Justice O'Connor).

A simplicidade novamente cedeu à tentação de princípios conflitantes. Sim, os estudantes/editores cristãos certamente tinham direitos de liberdade de expressão contra a universidade patrocinada pelo governo. A Justice O'Connor percebeu muito bem que, se o financiamento violava a "establishment clause", os direitos dos estudantes teriam que ceder à regra embutida; o resultado confuso de Everson deu a ela, e à Corte, uma forma a permitir que a universidade pública subsidiasse um jornal evangélico estudantil.

O entendimento de nossa Primeira Emenda sobre a Igreja e o Estado é até hoje confuso; na verdade, ele está "em frangalhos", como descrito pelo Justice Clarence Thomas, que também contribuiu para a confusão em um nível básico (SUPREME COURT OF THE UNITED STATES, 2011). ${ }^{30}$ Everson acrescentou, em plena medida, por meio de sua escorregadia fuga da retórica estrita, à bagunça criada pela flexibilidade.

\footnotetext{
${ }^{30}$ Justice Thomas, ao discordar de um certiorari [termo jurídico que se refere à garantia de revisão de uma decisão judicial (N. do E.)] negado em US Highway Patrol v. American Atheists. Thomas queria julgar o caso porque "a corte deveria estar fortemente envolvida pela cláusula de estabelecimento." No entanto, ele contribuiu muito para o caos como o único juiz que pretendia superar a decisão de Everson ao considerar que os estados, como o governo federal, estão vinculados a respeitar a separação entre Igreja e Estado. Como esse respeito deve ser demonstrado não está claro, mas pelo menos o caso de 1947 vinculou os estados e as localidades em aderir às regras federais restritivas das promoções de religiões, como em imagens, atividades, na educação e com ajuda fiscal. O Justice Thomas deixaria os estados livres para criarem suas próprias relações entre Estado e Igreja.
} 
De fato, quando as cortes saqueiam os textos e deformam de modo flexível os significados originais, elas forçam os advogados e Justices a lidar com o seu erro e voltar ao acerto. Entre o erro e a correção, há muito sofrimento ao longo de muito tempo.

V. E isso nos leva a District of Columbia v. Heller (SUPREME COURT OF THE UNITED STATES, 2008), um caso decidido pelo Justice que mais se declara "textualista", Antonin Scalia. Em um livro recente sobre interpretação jurídica, Scalia e seu coautor Bryan Garner "buscam restaurar [!] convenções interpretativas eficazes... [No entanto, Scalia] não garante que as suas decisões futuras estarão em conformidade com o que está escrito aqui” (SCALIA; GARNER, 2012, p. xxviii-xxx). Ele confessa imediatamente que o textualismo estrito que seu livro defende cederá, sempre que necessário e por motivos de adequação, às mais elásticas necessidades do século XXI. Assim, o mais alto defensor do "originalismo" na Suprema Corte mostra a que veio. Mas que "restauração"! Muito semelhante à posição da Igreja Católica em relação à Vichy - acreditamos em uma coisa, mas ajustaremos essa crença infinitamente quando colocada em discussão -, Justice Scalia propõe a fé de olhar apenas para o texto como teria sido entendido na época constituinte mas, em seguida, garante que ele vai quebrar essa fé sempre que a conveniência assim o exigir. Não pela primeira vez, ${ }^{31} \mathrm{Scalia}$ em Heller consegue evitar o seu próprio chamado "rigor" e manobra o texto constitucional de uma maneira que teria agradado aos decididos "construcionistas soltos" do primeiro movimento cristão.

Heller deu a Scalia, assim como havia ocorrido com os Justices Bradley e Holmes há mais tempo, a oportunidade de interpretar uma das Emendas à Constituição que ainda não haviam sido interpretadas.

A Segunda Emenda (U. S. CONSTITUTION, 1791) diz: "Sendo necessária à segurança de um Estado livre a existência de uma milícia bem organizada, o direito do povo de possuir e portar armas não poderá ser impedido."

Em Heller, a maioria da Corte detectou, ao longo deste texto, que todos fomos agraciados com o direito individual de possuir armas. Indiscutivelmente, o claro significado da Emenda, juntamente com sua sintaxe, fala de salvaguardar o direito do estado a ter uma milícia armada. Como duas dissidências vigorosas (de Stevens e Breyer) elaboraram de forma convincente, com a ajuda de professores de literatura e linguística que atuaram como

\footnotetext{
${ }^{31}$ Cf. algumas das inconsistências de Scalia em Jack Balkin (2011, n.3, p.7-8, 124-5). Cf. também uma crítica ao textualismo pelo juiz federal Richard Posner (2012, p.18). 
amicus, ${ }^{32}$ as primeiras palavras parecem limitar as demais, de modo que os constituintes pareciam incentivar o controle, pelas milícias estaduais, dos potenciais déspotas nacionais. Eles não falam de um direito pessoal de manter armas de fogo para fins de autodefesa ou para a caça ou para impressionar os vizinhos.

Scalia, em decisão de sessenta e quatro páginas, que é muito menos um modelo de clareza do que a Emenda que ele tanto acusa de ambiguidade, consegue acabar quase inteiramente com as palavras do que ele rotula de "cláusula de prefácio", concentrando-se na “cláusula operativa" para, então, dissociá-las. Mas como a frase "possuir e portar armas" por si só dificilmente mostra que a posse de armas de fogo para defesa pessoal poderia ser garantida, Scalia precisava ser ágil até mesmo em relação à “frase operativa” lida por si só. "Possuir" parece, à primeira vista, uma condição precedente ao ato de portar (ou usar armas); se isso for verdade, então o direito aplica-se para assegurar a prontidão em casos de conflito armado, o que é uma guerra e não autodefesa, caça ou qualquer outra coisa.

A metade "textualista" do originalismo, a única que Scalia valoriza, tem se provado ilusória quando é necessário mostrar que aquelas vinte e seis palavras da Segunda Emenda tratam do direito individual de portar armas. A outra âncora do "originalismo", a intenção dos constituintes, é geralmente desprezada por Scalia por ser impossível de ser encontrada e quase sempre indeterminada, ${ }^{33}$ mas ele é forçado pelas presentes circunstâncias a tentar responder à dissidência do Justice Stevens de que a história americana situa o direito de portar armas em milícias e não em autodefesa pessoal. Os constituintes tinham em mente um estado de prontidão contra a ameaça do poder nacional tirânico. Ao insistir que um grupo de homens em cada estado tivesse permissão para "possuir" armas, eles forjaram um compromisso - mas não um que Avishai Margalit (2010) teria rotulado como "podre" - com os seus colegas antifederalistas que desconfiavam do poder nacional. Como Scalia sente o dever de comunicar: "Os requerentes apontam para as leis da milícia do período de fundação que exigiam aos milicianos 'possuir' armas [apenas] em conexão com o serviço da milícia e eles concluem daí que a expressão 'possuir armas' tem uma conotação relacionada com a milícia" (SUPREME COURT OF THE UNITED STATES, 2008). Mais tarde, porém - encarnando o

\footnotetext{
${ }^{32}$ Cf. Brief for Professors of Linguistics and English... (SUPREME COURT OF THE UNITED STATES, 2008), submetido à Suprema Corte em Heller.

${ }^{33}$ Uma reconhecida afirmação de Scalia sobre seu próprio ceticismo ao esmiuçar as intenções dos constituintes é "Os homens podem pretender o que quiserem, mas só as leis que promulgam nos vinculam” (GUTMANN, 1997, p.16-7). O método textualista (ou de significado claro) - pelo menos quando se acaba com qualquer tipo de investigação sobre a intenção dos criadores humanos do texto - foi amplamente criticado (mesmo quando utilizado de forma consistente, o que Scalia não vem fazendo). Cf., por exemplo, FISH, 2008, p. 1109 et seq.

Revista da Faculdade de Direito - UFPR, Curitiba, vol. 59, n. 2, p. 9-30, 2014.
} 
papel, talvez, de um São João contemporâneo - Scalia ridiculariza esta leitura plausível e os Justices dissidentes (flexifóbicos) que a defendiam:

\begin{abstract}
Eles fabricaram uma definição híbrida, em que "portar armas" conota a carga real de carregar armas (e, portanto, não é realmente uma locução), mas somente a serviço de uma milícia organizada [de modo que]... a expressão "possuir e portar armas" seria incoerente. A palavra "armas" teria dois significados diferentes ao mesmo tempo: "armas" (como objeto de "possuir") e (como objeto de "portar") metade de uma locução ["portar armas contra"]. Seria mais ou menos como dizer "encheu e chutou o balde" para significar "Ele encheu o balde e morreu". Grotesco. (Ibid.)
\end{abstract}

Podemos concordar que isso é "grotesco", mas nos referimos às palavras de Scalia, não a de seus adversários. Ou talvez ele tenha sido apenas "muito inteligente pela metade"34 ou - de modo mais sério, porque já vimos manobras interpretativas como esta nas páginas deste livro - ele pode ter se utilizado de uma técnica de mentira contra o texto, pela qual todos os meios para se obter o fim desejado são permitidos. Ele não pode negar que "possuir e portar" formam uma frase totalmente coerente, por isso ele insiste que "portar armas" só pode significar "fazer guerra" se for seguido da palavra "contra". Por mais imprecisa que esta manobra seja, ela falha sempre que retornarmos à primeira parte da Emenda: pois se eu digo, de forma análoga: "Se hoje o tempo estiver agradável, eu farei um piquenique", minha intenção é agregar à atividade pretendida uma condição precedente, qual seja, o tempo agradável. Se o tempo piorar eu não quero mais fazer o piquenique; quando a necessidade de uma milícia é extirpada, o direito de possuir e portar armas, por qualquer motivo, é atenuado.

A sabedoria comum é que apenas Cortes flexíveis ou "ativistas", desvinculadas das tradições e significados originais, podem manter a nossa Constituição diante dos novos tempos. Na verdade, os casos que indiquei aqui mostram que os problemas surgem quando significados simples e (o que é pior) as intenções são traídos por juízes que decidem de maneira flexível, ao invés de literal, especialmente na primeira decisão sobre um tema, o que exigirá posteriormente muito trabalho de limpeza e restauração por Cortes flexifóbicas.

\title{
REFERÊNCIAS
}

BALKIN, Jack M. Living Originalism. Cambridge, MA: Harvard University Press, 2011.

\footnotetext{
${ }^{34}$ Este apelido, "muito inteligente pela metade", descreve uma subcategoria de infinita maleabilidade que parece paradoxal. Não é a análise detalhada de um texto algo relativamente claro que tem sido associado, através dos milênios, com o leitor "Farisaico", o "Talmudista", o "estudioso judeu"? Ainda, para tocar o tema apenas de forma preliminar - a tradição oral judaica, os sofismas parecem uma característica de outras tradições mais maleáveis, nas quais todo o texto pode ser manipulado sem restrição aparente.
}

Revista da Faculdade de Direito - UFPR, Curitiba, vol. 59, n. 2, p. 9-30, 2014. 
BRENNAN, William. The Constitution of the United States: Contemporary Ratification. In: LEVINSON, Stanford; MAILLOUX, Steven (Ed.). Interpreting Law and Literature. Evanston, IL: Northwestern University Press, 1988. p. 13-24.

BREST, Paul. The Misconceived Quest for the Original Understanding. Boston University Law Review, v. 60, 1980.

DWORKIN, Ronald. Taking Rights Seriously. Cambridge, MA: Harvard University Press, 1978. P. 14-80.

FAULKNER, William. Intruder in the Dust. New York: Vintage, 1996. First published 1948.

FISH, Stanley. Intention is all there is: a Critical Analysis of Aharon Barak's Purposive Interpretation in Law. Cardozo Law Review v. 29, p. 1109, 2008.

GREENAWALT, Kent. Legal Interpretation: Perspectives from Other Disciplines and Private Texts. New York: Oxford University Press, 2010.

GUNTHER, Gerald. Clear and Present Danger in the Forties: Widening Use, Rising Dissatisfaction. In: GUNTHER, Gerald. Constitutional Law. 12. ed. Westbury, NY: Foundation Press, 1991.

. Learned Hand and the Origins of Modern First Amendment Doctrine: Some Fragments of History. Stanford Law Review, v. 27, 1975.

GUTMANN, Amy. A Matter of Interpretation: Federal Courts and the Law. Princeton, NJ: Princeton University Press, 1997.

GUTMANN, Amy; THOMPSON, Dennis. The Spirit of Compromise: Why Governing Demands It and Campaigning Undermines It. Princeton, NJ: Princeton University Press, 2013.

HIGGENBOTHAM JR., Leon. Keeping Thurgood Marshall's Promise. Harvard Blackletter Journal, v.16, 2000.

HOLDSWORTH, William Searle. A History of the English Law. London: Methuen \& Company Limited, 1903. v. IX.

JEFFERSON's Wall of Separation Letter. Disponível em: <http://www.constitution.org/tj/sep_church_state.htm>. Acesso em: 11 mar. 2014.

JOHNSON, Frank M. Whose Rulings Helped Desegregate the South. New York Times, p. A12, July 241999.

JUSTICE Ginsburg's Misdirection. The New York Times. New York, 2 abr. 2013. Editorial.

LANDAU, Michael. Fordham Intellectual Property, Media \& Entertainment Law Journal, v. 22, p. 513, 2012. 
State Sovereign Immunity and Intellectual Property Revisited. 2012. Disponível em: $<$ http://heinonline.org/HOL/LandingPage?handle=hein.journals/ frdipm22\&div=20\&id=\&page $=>$. Acesso em: 11 mar. 2014.

LEVINSON, Sanford. Constitutional Faith. Princeton, NJ: Princeton University Press, 1988.

Framed: America's 51 Constitutions and the Crisis of Governance. New York: Oxford University Press, 2012.

Our Undemocratic Constitution. New York: Oxford University Press, 2006.

MARGALIT, Avishai. On Compromise and Rotten Compromises. Princeton, NJ: Princeton University Press, 2010.

MARRUS, Michael; PAXTON, Robert. Vichy France and the Jews. New York: Basic Books, 1981.

PELIKAN, Jaroslav. Interpreting the Bible and the Constitution. New Haven, CT: Yale University Press, 2004.

POSNER, Richard. Review: The Spirit Killeth, but the Letter Giveth Life. In: The New Republic, September 13, 2012.

RELIGION and politics on Easter Sunday. CBS News/Face the Nation. Entrevista de 31 de março de 2013, organizada por Bob Schieffer. Disponível em: $<$ http://www.cbsnews.com/news/face-the-nation-transcripts-march-31-2013-religion-andpolitics-on-easter-sunday/>. Acesso em: 11 mar. 2014.

SCALIA, A.; GARNER, Bryan A. Reading Law. Eagan, MN: Thomson Reuters, 2012.

SUPREME COURT OF THE UNITED STATES. Abrams v. U S , 250 U.S. 616 (1919). Disponível

em:

$<$ http://caselaw.lp.findlaw.com/scripts/getcase.pl?court=US\&vol=250\&invol=616>. Acesso em: 11 mar. 2014.

Bradwell v. State of Illinois, 83 U.S. 130 (1872). Disponível em: $<$ http://caselaw.lp.findlaw.com/scripts/getcase.pl?navby=case $\&$ court=us \&vol=83\&page=130 $>$. Acesso em: 11 mar. 2014.

Brandenburg v. Ohio, 395 U.S. 444 (1969). Disponível em: $<$ http://caselaw.lp.findlaw.com/scripts/getcase.pl?court=US\&vol=395\&invol=444>. Acesso em: 11 mar. 2014.

Brief for Professors of Linguistics and English Dennis E. Baron, Ph.D., Richard W. Bailey, Ph.D. and Jeffrey P. Kaplan, Ph.D. in Support of Petitioners. 11 jan. 2008. Disponível em:

<http://www.americanbar.org/content/dam/aba/publishing/preview/publiced_preview_briefs_ pdfs_07_08_07_290_PetitionerAmCu3LinguisticsEnglishProfsnew.authcheckdam.pdf>. Acesso em: 11 mar. 2014. 
Brown v. Board of Education, 347 U.S. 483 (1954). Disponível em: $<\mathrm{http}$ //caselaw.lp.findlaw.com/scripts/getcase.pl?court=US\&vol=000\&invol=07-290>. Acesso em: 11 mar. 2014.

District of Columbia et al. v. Heller (2008). Disponível em: <http://caselaw.lp.findlaw.com/scripts/getcase.pl?court=US\&vol=000\&invol=07-290>. Acesso em: 11 mar. 2014.

Everson v. Board of Education of Ewing tp., 330 U.S. 1 (1947). Disponível em: $<$ http://caselaw.lp.findlaw.com/cgi-bin/getcase.pl?court=US\&vol=330\&invol=1 >. Acesso em: 11 mar. 2014.

. Hans v. State of Louisiana, 134 U.S. 1 (1890). Disponível em: $<$ http://caselaw.lp.findlaw.com/scripts/getcase.pl?court=US\&vol=134\&invol=1>. Acesso em: 11 mar. 2014.

. Parden v. Terminal R. Co., 377 U.S. 184 (1964). Disponível em: $<$ http://caselaw.lp.findlaw.com/scripts/getcase.pl?court=US\&vol=377\&invol=184>. Acesso em: 11 mar. 2014.

Petty v. Tennessee-Missouri Comm'n., 359 U.S. 275 (1959). Disponível em: $<$ http://caselaw.lp.findlaw.com/scripts/getcase.pl?court=US\&vol=359\&invol=275>. Acesso em: 11 mar. 2014.

Plessy v. Ferguson, 163 U.S. 537 (1896). Disponível em: <http://caselaw.lp.findlaw.com/scripts/getcase.pl?court=US\&vol=163\&invol=537>. Acesso em: 11 mar. 2014.

Rosenberger v. University of Virginia, 515 U.S. 819 (1995). Disponível em: $<$ http://caselaw.lp.findlaw.com/scripts/getcase.pl?navby=case \&court=us\&vol=515\&page $=81$ 9>. Acesso em: 11 mar. 2014.

Schenck
$<$ http://caselaw.lp.findlaw.com/scripts/getcase.pl?court=US\&vol=249\&invol=47>. Acesso em: 11 mar. 2014.

US Highway Patrol v. American Atheists, 565 U.S. (2011). Disponível em: $<$ http://caselaw.lp.findlaw.com/scripts/getcase.pl?court=US\&vol=000\&invol=10-1276>. Acesso em: 11 mar. 2014.

U. S. CONSTITUTION. Eleventh Amendment - Suits Against States. 1798. The Judicial power of the United States shall not be construed to extend to any suit in law or equity, commenced or prosecuted against one of the United States by Citizens of another State, or by Citizens or Subjects of any Foreign State. Disponível em <http://constitution.findlaw.com/amendment11/amendment.html\#sthash.1YcD3Fzu.dpuf > Acesso em: 11 mar. 2014. 
. First Amendment - Religion and Expression. Congress shall make no law respecting an establishment of religion, or prohibiting the free exercise thereof; or abridging the freedom of speech, or of the press; or the right of the people peaceably to assemble, and to petition the Government for a redress of grievances. 1791. Disponível em <http://constitution.findlaw.com/amendment1/amendment.html\#sthash.g817jetT.dpuf > Acesso em: 11 mar. 2014.

Fourteenth Amendment - Rights Guaranteed Privileges and Immunities of

Citizenship, Due Process and Equal Protection. 1868. Disponível em <http://constitution.findlaw.com/amendment14/amendment.html\#sthash.pjekPR4S.dpuf > Acesso em: 11 mar. 2014.

Second Amendment - Bearing Arms. A well regulated Militia, being necessary to the security of a free State, the right of the people to keep and bear Arms, shall not be infringed. 1791.

Disponível

em

<http://constitution.findlaw.com/amendment2/amendment.html\#sthash.wOsuRLxJ.dpuf>

Acesso em: 11 mar. 2014.

WECHSLER, Herbert. Toward Neutral Principles of Constitutional Law. Harvard Law Review, v. 73, 1959, p. 1-35.

WEISBERG, Richard $\mathrm{H}$. On the Use and Abuse of Nietzsche for Modern Constitutional Theory. In: LEVINSON, Stanford; MAILLOUX, Steven (Ed.). Interpreting Law and Literature. Evanston, IL: Northwestern University Press, 1988, p. 181-92.

Text into Theory: A Literary Approach to the Constitution. Georgia Law Review, v. 20, 1986. (Reimpresso e revisado em: Levinson e Mailloux, Interpreting Law and Literature, nota 3, p. 181-93).

\section{FLEXIBLE DISTORTIONS OF AMERICAN LAW, OR HOW ST. PAUL AND ST. JOHN INFLUENCE FUNDAMENTAL SOCIAL POLICY}

ABSTRACT: This article aims to demonstrate how to preserve the possibility of a laudable change within interpretive limits, through the gradual restoration of five flexible misreadings of the US Constitution.

KEYWORDS: American law. Flexible misreadings. Interpretive limits. US Constitution. 